\title{
Impacto da Regulamentação SPS e TBT nas Exportações Brasileiras de Uva no Período de 1995 a 2009
}

\author{
Greigiano José Alves ${ }^{1}$, Marília Fernandes Maciel Gomes², \\ Fernanda Maria Almeida ${ }^{3}$ e Lílian Valeriano Gonçalves ${ }^{4}$
}

Resumo: A cadeia produtiva da uva tem importância ímpar quanto à geração de renda e de emprego para diversas economias regionais. Todavia, nos últimos anos, o comércio internacional deste setor, assim como de todo o setor frutícola, tem enfrentado a imposição de diversas medidas não tarifárias, entre as quais, as sanitárias, fitossanitárias e técnicas. Assim, neste trabalho, são analisados os efeitos das normas sanitárias, fitossanitárias e técnicas impostas pelos países importadores de uva brasileira, no período de 1995 a 2009. Para este fim, foram feitas uma análise de inventário e uma abordagem econométrica, em que se fez uso do modelo gravitacional, com o objetivo de verificar o impacto de tais medidas na exportação de uva brasileira. Pelos resultados encontrados na análise de inventário, foi possível constatar relação positiva entre a evolução do número de notificações e a evolução das importações. Já pelo modelo econométrico, descartou-se a possibilidade de tais medidas terem afetado negativamente o comércio, tendo sido, no caso das medidas sanitárias e fitossanitárias, encontrada uma relação positiva com as exportações de uvas, ou seja, essas medidas auxiliaram o comércio, e os efeitos das medidas técnicas sobre as exportações foram nulos.

Palavras-chaves:Modelogravitacional, medidas nãotarifárias, comérciointernacional, produção integrada de frutas.

\footnotetext{
Abstract: The grape production chain has unique importance regarding to generate income and employment for many regional economies. However, in recent years, international trades in this sector, as well as the entire fruit sector, have been facing the imposition of various non-tariff measures, including sanitary, phytosanitary and technical. Thus, this paper analyzes the effects of sanitary, phytosanitary and technical rules imposed by

1. Doutorando em Economia Aplicada, ESALQ-USP. E-mail: alvesufv@gmail.com

2. Professora do Departamento de Economia Rural - Universidade Federal de Viçosa. E-mail: mfmgomes@ufv.br

3. Professora do Departamento de Administração e Contabilidade - Universidade Federal de Viçosa. E-mail: fernanda.almeida@ufv.br

4. Professora da Faculdade Unec. E-mail: lilianvgoncalves@yahoo.com.br
} 
importing countries of the Brazilian grape, from 1995 to 2009. To this end, we made an analysis of inventory and an econometric approach, in which we used the gravity model, in order to verify the impact of such measures on the Brazilian shipments of grape. The results found in the inventory analysis showed a positive relationship between changes in the number of notifications and import trends. As for the econometric model, the possibility of such measures have negatively affected the trading was disregarded and, in the case of sanitary and phytosanitary measures, a positive relationship with grape exports was found, i.e., they helped trades and effects of technical measures on exports were zero.

Key-words: Gravity model, non-tariff barriers, international trade, integrated fruit production.

Classificação JEL: F13.

\section{Introdução}

A cadeia produtiva de frutas é importante para a geração de renda e entrada de divisas para o País. Entre as diversas espécies de frutas, a produção de uva vem se tornando uma atividade promissora quanto à geração de renda e de trabalho para diversos polos regionais.

Em 2009, o Brasil produziu 1,3 milhão de toneladas de uva, queda de $4,08 \%$ em relação ao ano anterior. Desse total, 678.169 toneladas foram destinadas ao consumo in natura e 667.550, ao processamento de vinho. Os estados que mais produziram uva foram o Rio Grande do Sul, São Paulo, Pernambuco e Paraná com, respectivamente, 737,3, 177,9, 158,5 e 102 mil toneladas (MELLO, 2010).

Quanto ao comércio internacional, o valor das exportações brasileiras de uva em 2011 foi de US\$ 135,7 milhões, crescimento de mais de $800 \%$ comparativamente ao ano de 2000, que totalizou US\$ 14,6 milhões (ALICEWEB, 2012). Os principais países importadores de uva brasileira, no período de 1995 a 2009, foram Holanda (que em determinados anos foi responsável por mais de 50\% das importações), Reino Unido, Argentina e Estados Unidos. Na Tabela 1A, presente no anexo, estão listados os cinco países que mais importaram uva brasileira para cada ano no período de 1995 a 2009.

Todavia, a participação brasileira no comércio internacional de uva tem sido pequena ao longo do tempo. De 1995 a 2004, as exportações brasileiras representaram, em média, $1,6 \%$ do total exportado no mundo. Já no período de 2005 a 2008, observou-se aumento considerável dessa participação, que passou a ser de, em média, 6,5\% do volume transacionado no mercado externo, e queda no período posterior, de 2009 a 2011, com média de 4\% (UNCOMTRADE, 2012).

Ferreira et al. (2010) citam dois fatores importantes dessa pequena participação da uva brasileira no cenário internacional. O primeiro seria o mercado interno, que demanda mais de $50 \%$, tanto no consumo de uva in natura quanto no consumo de produtos processados; e o segundo seriam as barreiras tarifárias ou não tarifárias. Já Andrigueto et al. (2008) citam também a falta de marketing para as frutas tropicais, além do fato de a maior parte das frutas comercializadas no mundo serem de clima temperado, enquanto as frutas brasileiras são de clima tropical.

Quando se analisa o cenário mundial nas últimas décadas, verifica-se crescente utilização, por parte de diversos países, de medidas não tarifárias $(\mathrm{MNT})^{5}$ em substituição às barreiras tarifárias, que vêm sendo reduzidas desde a primeira rodada

5. Neste trabalho, o termo barreira não tarifária foi substituído por medida não tarifária pelo fato de uma medida poder favorecer o fluxo internacional de comércio, sendo considerada somente barreira caso a medida seja desfavorável ao fluxo internacional de comércio. 
de negociação multilateral de comércio, devido a acordos bilaterais e à criação de blocos econômicos. O setor de fruticultura, similar a outros setores, tem enfrentado a imposição dessas medidas não tarifárias (FARIAS, 2004). Essas medidas não tarifárias (técnicas e não técnicas) incluem as medidas sanitárias e fitossanitárias (SPS) e técnicas (TBT), controle de preços, cotas, entre outras.

O Brasil, ciente da necessidade de se adequar às normas impostas pelos países importadores, criou o programa de Produção Integrada de Frutas (PIF), que contém normas sanitárias, fitossanitárias e técnicas para a produção de mais de 18 tipos de culturas. Esse sistema foi implantado pelo governo federal em razão da demanda do setor frutícola do País, em especial o de maçã. O PIF teve início em 1998, e as primeiras normas foram lançadas pelo governo, em 2002, para a produção de maçã e, em 2003, para a de uva.

Nesse sentido, dado o potencial de crescimento da vitivinicultura no Brasil, tanto no consumo doméstico quanto na pauta de exportações, foram analisados os efeitos das exigências sanitárias, fitossanitárias e técnicas notificadas à OMC pelos países importadores da uva in natura brasileira, denominada daqui para frente apenas uva. Foi verificado também o impacto do programa de Produção Integrada de Frutas no comércio internacional da uva brasileira.

Diversos autores, como Burnquist e Souza (2010), Roberts e Unnevehr (2005) e Josling et al. (2004), entre outros, analisaram o impacto das medidas não tarifárias no comércio internacional. Burnquist e Souza (2010) analisaram os efeitos das MNT's, notadamente aquelas associadas à natureza sanitária e fitossanitária, no comércio bilateral entre 43 países, entre 2003 e 2006. Robert e Unnevehr (2005) verificaram que os Acordos SPS eliminaram diversas barreiras regulamentares desnecessárias ao comércio, apontando, segundo as evidências, ter havido progresso limitado na redução de custos regulatórios nas transações do comércio de alimentos. Já Josling et al. (2004) verificaram que a supervisão internacional de regulamentação na área de alimentos foi construtiva.
Em relação aos produtos do agronegócio brasileiro, podem ser citados os trabalhos desenvolvidos por Cajazeira (2008), Junqueira (2006), Farias (2004), Dias (2003) e Miranda (2001). No entanto, constatou-se que há pouca informação sobre o impacto de tais medidas na cadeia produtiva da uva. Portanto, este trabalho pretende contribuir para a literatura ao verificar se as medidas SPS e TBT impostas à uva brasileira são protecionistas ou não e se o programa PIF está sendo efetivo, resultando em maiores volumes da uva brasileira exportados.

Este trabalho é constituído por seis partes, além desta introdução. Na segunda, são apresentadas uma revisão dos conceitos de medidas não tarifárias e uma descrição do PIF; na terceira parte, descreve-se o referencial teórico; na quarta, é apresentado o referencial analítico; na quinta, são discutidos os resultados; e, por fim, na sexta parte, a conclusão é apresentada.

\section{Medidas não tarifárias e sistema de produção integrada de frutas}

\subsection{Medidas não tarifárias: acordos SPS e TBT}

As negociações multilaterais sobre liberalização do comércio foram iniciadas em 1947, em Genebra, com a criação do General Agreementon Tariffs and Trade (GATT). A partir daí, foram realizadas mais oito rodadas. Na penúltima, a Rodada do Uruguai (1986-93), foi criada a Organização Mundial de Comércio (OMC). Em relação ao debate sobre barreiras não tarifárias, elas só tiveram importância preponderante diante das barreiras tarifárias na sétima rodada, ou a sexta após a criação do GATT, a Rodada de Tóquio (1973-79) (PEREIRA, 2005).

Medidas não tarifárias podem ser definidas como todo o tipo de medida não imposta sob a forma de tarifa ao comércio internacional. Essas medidas podem ser restritivas à livre entrada de mercadorias importadas, que, neste caso, é considerada uma barreira não tarifária, ou impulsiona- 
dora do comércio entre as nações, apreciada como facilitadora de comércio. Como exemplo de medidas não tarifárias, podem ser citadas: medidas técnica, fitossanitária e sanitária, cotas, exigência ambiental ou social, restrições voluntárias às exportações, exigências gerenciais, entre outras. As barreiras técnicas são restrições relacionadas às características do produto, modo de produção, embalagens, entre outras. Barreiras fitossanitárias e sanitárias são medidas que têm como objetivo proteger animais e plantas de disseminação de doenças e pragas e proteger a saúde humana e animal de contaminantes, aditivos, toxinas, agrotóxicos (THORSTENSEN, 1999).

Os acordos SPS e TBT originaram-se do antigo Código de Normas, ou Standards Code, estabelecido na Rodada Tóquio. A adesão ao Código de Normas era voluntária e tinha com objetivo disciplinar o tema de regulamentos técnicos, incluindo as medidas de natureza sanitária (MIRANDA et al., 2004). Este acordo não foi muito eficaz, sendo substituído, na Rodada do Uruguai, pelo novo Acordo sobre Barreiras Técnicas ao Comércio da OMC (WTO - Agreement on Technical Barriers to Trade - o Acordo TBT), tornando mais rígidas as disciplinas do Código de Normas. O Acordo TBT é aplicado de forma ampla a regulamentos técnicos e padrões, inclusive àqueles que têm por objetivo a proteção à saúde. Contudo, os negociadores viram que as medidas sanitárias e fitossanitárias mereciam regras especiais, separadas daquelas aplicáveis à categoria ampla dos regulamentos técnicos e padrões. Assim, um acordo separado, o Acordo SPS, foi concluído para tratar especificamente das medidas sanitárias e fitossanitárias (UNCTAD, 2003).

O acordo SPS obriga cada membro da OMC a notificar à entidade a adoção de medidas sanitárias ou fitossanitárias que venham a ter potencial impacto sobre o comércio internacional; já o acordo TBT visa facilitar o comércio internacional, criando condições para eliminar as barreiras técnicas desnecessárias ao comércio (SILVA et al., 2010). Vale ressaltar que a OMC não proíbe a aplicação de normas e regulamentos sanitários, fitossanitários e técnicos, mas tem como objetivo impedir que tais instrumentos sejam utilizados de forma a prejudicar o comércio internacional.

A imposição de uma regulamentação por parte do governo pode ocorrer, segundo Burnquist e Souza (2010), com o objetivo de atender a certas necessidades do consumidor quanto à saúde e segurança alimentar, devido à proteção ambiental, de fornecer ao consumidor informações adicionais de forma a compensar os problemas de competição imperfeita relacionados à informação incompleta, ou ainda, conforme Souza et al. (2007), pela pressão de setores menos competitivos.

Alguns trabalhos empíricos têm sido elaborados com vistas a verificar o impacto das barreiras não tarifárias sobre o comércio. Segundo Moenius (2004), normas específicas, típicas de produtos manufaturados entre países, tendem a promover o comércio internacional e não inibi-lo. Isso ocorre devido aos custos de transação associados à informação incompleta. Quando não há normas bem definidas, o custo de obter informações a respeito dos produtos é elevado, o que causa um impacto negativo no comércio. Portanto, se o uso de normas impostas por grupos de países reduzir os custos de transação, haverá benefício para o comércio internacional.

Procurando verificar os efeitos das notificações sanitárias e fitossanitárias no comércio internacional de bens manufaturados, Burnquist e Souza (2010) encontraram resultados ambíguos. Os autores reconhecem a necessidade de se analisarem as notificações não de forma agregada, mas desagregada, a fim de obter resultados mais específicos.

Já no trabalho de Disdier et al. (2008), foi diagnosticado que as barreiras SPS e TBT causam impactos negativos no comércio de bens agrícolas entre os membros da $\mathrm{OCDE}^{6}$ e os países em desenvolvimento; porém, não causam distorções no comércio entre os primeiros. Os autores concluíram também que as notificações feitas pela União Europeia restringiram mais o fluxo comercial do que as emitidas pelos demais países membros da OCDE.

6. Organization for Economic Co-operation and Development. 
Henson e Loader (2001) afirmam que as medidas sanitárias e fitossanitárias são fatores importantes que influenciam a capacidade dos países em desenvolvimento para explorar novas oportunidades de exportação de produtos agrícolas e alimentares nos mercados dos países desenvolvidos.

Desse modo, de acordo com a literatura consultada, os efeitos das medidas sanitárias, fitossanitárias e técnicas podem ser benéficos ao comércio, sendo que, neste caso, tais medidas agirão como facilitadoras do comércio, podendo também restringi-lo.

\subsection{Sistema de Produção Integrada de Frutas (PIF)}

No Brasil, o sistema de Produção Integrado de Frutas (PIF) foi implantado entre 1998 e 1999, tendo como motivo a necessidade de os exportadores de maçã se adequarem às exigências impostas pela União Europeia. Em 2002, foram publicadas as normas para a produção de maçã e, em 2003, para a produção de uva.

A implantação da PIF permite a gestão ambiental das atividades agrárias de forma sustentável ao estabelecer normas assegurando uma cuidadosa utilização dos recursos naturais, minimizando o uso de agrotóxicos e insumos na exploração. $\mathrm{O}$ sistema PIF tem por base as normas da série ISO 14001, além de possibilitar também a aplicação da norma ISO 9001, referente ao acompanhamento da cadeia produtiva e da pós-colheita orientado à produção de produtos agrícolas de qualidade internacional que atendam às necessidades e exigências do consumidor final. Além disso, o Programa de Produção Integrada de Frutas do Brasil segue todas as normas impostas pelo Codex Alimentarius no que se refere ao limite máximo de resíduos de defensivos (BUAINAIN e BATALHA, 2007).

Em 2007, havia 352 produtores de uva cadastrados no sistema PIF, com produção de 167.272 toneladas, 74 deles já certificados, com produção de 41.568 toneladas. O sistema PIF tem como princípio "a visão sistêmica, inicialmente no manejo integrado de pragas, evoluindo para a integração de processos em toda a cadeia produtiva" (ANDRIGUETO et al., 2008). Dessa forma, a implan- tação da Produção Integrada de Frutas deve ter uma visão holística e estruturada sob quatro pilares de sustentação: organização da base produtiva, sustentabilidade do sistema, monitoramento dos processos e informação e banco de dados e componentes que interliguem e consolidem os demais processos (ANDRIGUETO et al., 2008).

Conforme esses autores, os seguintes resultados podem ser atribuídos ao PIF: um aumento tanto da produtividade quanto da qualidade do produto; uma redução do consumo de água e de energia elétrica; maior biodiversidade e população de inimigos naturais das pragas; redução da aplicação de agrotóxicos e redução da presença de resíduos químicos no produto; racionalização no uso dos insumos; melhoria do meio ambiente e melhoria da saúde do trabalhador rural e do consumidor final. De acordo com a Embrapa, em 2004, a redução, em percentagem, de inseticidas, fungicidas e herbicidas, na produção de uva, foi de, respectivamente, 53, 43,3 e 60,5. Esses valores mostram a importância do sistema PIF na redução do uso de agrotóxicos, visto que o programa passou a ser implantado em 2003.

A importância da produção integrada de frutas comparativamente ao método tradicional é ressaltada por Buainain e Batalha (2007), que apontam que alguns países europeus praticamente não importam frutas produzidas pelo método tradicional. Citam, neste contexto, a Suíça e a Dinamarca, além da União Europeia, que, em 2003, proibiu a entrada de maçã brasileira, nos países membros, produzidas pelo método convencional.

O sistema PIF, conforme Cintra et al. (2005), é um programa regulamentado pelo Brasil e se difere em alguns pontos da Produção Integrada difundida nos principais produtores e importadores mundiais de frutas. Em cada país, há diferenças em suas normas quanto ao uso de produtos químicos, carências, manejo em geral etc. Nesse caso, o PIF não garante totalmente a aceitação do produto brasileiro no mercado externo, sendo necessário que a fruta brasileira que possua o selo de certificação do PIF necessita também da aprovação dos órgãos internacionais competentes que regulamentem e aceitem as condições 
do processo produtivo brasileiro. É claro que ao obter o selo de certificação brasileiro atestando a adesão ao PIF, o exportador está em larga vantagem aos demais, visto que o processo produtivo adotado pelo programa utilizou o mínimo de produtos químicos, além de seguir padrões de baixo impacto ambiental, principais fatores exigidos pelos importadores de frutas frescas.

No entanto, é importante mencionar que existem outros selos de certificação, diferentes do selo PIF, e que garantem ao produtor exportar seu produto. Neste caso, citam-se: European Retailers Produce Working Group - Good Agricultural Practices (EurepGAP, atualmente denominado GlobalGAP), selo exigido pela União Europeia; o Tesco Natural Choice (TNC), protocolo criado pela Tesco com sede no Reino Unido; e o APHIS (Serviço de Inspeção Sanitária de Animais e Vegetais), selo exigido pelos Estados Unidos.

\section{Modelo gravitacional}

Segundo a Lei de Gravitação Universal de Newton, a atração entre os corpos é relacionada diretamente com a massa de cada corpo e inversamente com a distância entre eles. No caso do comércio internacional, a adaptação é feita levando-se em consideração que os fluxos de comércios entre os países são diretamente relacionados com algumas variáveis de atração, como o PIB, e inversamente relacionados com algumas variáveis de "repulsão" que atuam como limitadores do comércio, como, por exemplo, a distância entre os países.

Um dos primeiros pesquisadores a utilizar o princípio da Lei de Gravitação Universal de Newton no comércio internacional foi Tinbergen (1962). Posteriormente, surgiram outros trabalhos que fizeram uso do modelo gravitacional no estudo do fluxo comercial entre os países, tendo inserido algumas modificações. Como exemplos, são citados: Anderson (1979), que assumiu como pressuposto que os países produzem tanto bens comercializáveis quanto não comercializáveis; Bergstrand (1985), que levou em considera- ção a dotação de fatores dos países; e McCallum (1995), que incorporou uma variável visando captar o efeito das fronteiras geográficas. Contudo, o modelo gravitacional ainda não detinha uma boa fundamentação teórica, que foi aprimorada no trabalho de Anderson e van Wincoop (2003).

Entre os diferentes autores que utilizaram o modelo gravitacional, estão: Mátyás (2002), que incorporou variáveis dummies na definição de blocos econômicos; Rose e Spiegel (2002), que buscaram verificar se países credores emprestam mais para países que partilham laços comerciais mais intensos; Azevedo (2004), que verificou os efeitos de comércio atribuídos somente à criação do Mercosul; Carrère (2006), que analisou o impacto de acordos regionais; Baier e Bergstrand (2007), que verificam o efeito do livre comércio; Silva et al. (2007), que verificaram o efeito fronteira para o caso brasileiro; e Burnquist e Souza (2010), que analisaram o impacto da regulamentação sanitária sobre o comércio.

Neste trabalho, foi utilizado o modelo teórico proposto por Anderson e van Wincoop (2003), em que os autores consideram uma função de demanda do tipo CES (Constant elasticity of substitution).

A equação gravitacional é definida como (ANDERSON e van WINCOOP, 2003):

$$
\begin{aligned}
& X_{i, j}^{k}=\frac{E_{j}^{k} Y_{i}^{k}}{Y^{k}}\left(\frac{t_{i, j}^{k}}{P_{j}^{k} \Pi_{i}^{k}}\right)^{1-\sigma_{k}} \\
& \left(\Pi_{i}^{k}\right)^{I-\sigma_{k}}=\sum_{j}\left(\frac{T_{i, j}^{k}}{P_{j}^{k}}\right)^{I-\sigma_{k}}\left(\frac{E_{j}^{k}}{Y^{k}}\right) \\
& \left(P_{j}^{k}\right)^{l-\sigma_{k}}=\sum_{j}\left(\frac{T_{i, j}^{k}}{\Pi_{j}^{k}}\right)^{1-\sigma_{k}}\left(\frac{Y_{i}^{k}}{Y^{k}}\right)
\end{aligned}
$$

em que $X_{i, j}^{k}$ representa as exportações para uma classe de produtos do setor $k$, do país $i$ (neste caso o Brasil) para o país $j$, no período $t ; E_{j}^{k}$, o dispêndio da economia do país $j ; Y_{i}^{k}$, o Produto Interno Bruto (PIB) do país $i$; $Y^{k}$ é a produção agregada mundial; $\sigma_{k}$, a elasticidade de substituição de importação entre todos os produtos; $T_{i, j}^{k}$, o custo de comércio incorrido pelos exportadores para o país impor- 
tador $j$; e $P_{j}^{k}$ e $\Pi_{j}^{k}$ representam índices de preços para o país exportador $i$ e do país importador $j$.

A partir das equações (1) a (3), Anderson e Van Wincoop (2003) definem a equação gravitacional, representada por:

$$
\begin{aligned}
& \ln \left(X_{i, j}^{k}\right)=\ln \left(E_{j}^{k}\right)+\ln \left(Y_{i}^{k}\right)-l\left(Y^{k}\right)+ \\
& +\sum_{m=1}^{M} \lambda_{m} \ln \left(z_{i, j}^{m}\right)-\left(1-\sigma_{k}\right) \ln \left(P_{j}^{k}\right)- \\
& -\left(1-\sigma_{k}\right) \ln \left(\prod_{i}^{k}\right)
\end{aligned}
$$

em que $z_{i, j}^{m}$ representa proxies representativas que captam os efeitos das barreiras ao comércio internacional dos custos de transação.

\section{Metodologia}

Esta seção está dividida em três partes. $\mathrm{Na}$ primeira, é apresentada a Análise de Inventário, sendo nela descrito o procedimento utilizado para se obter o Índice de Cobertura. Na segunda, é exposto o modelo econométrico, baseado no modelo gravitacional, proposto na seção anterior. Por fim, na terceira parte, são apresentadas as variáveis e as fontes de dados.

\subsection{Análise de inventário}

A análise de inventário, preconizada pela Conferência das Nações Unidas para o Comércio e o Desenvolvimento (UNCTAD), tem como objetivo quantificar, por meio de indicadores, o montante de comércio sujeito a uma determinada medida não tarifária sobre determinados setores ou países (LAIRD, 1996). Na literatura pesquisada, os índices mais utilizados são o Índice de Frequência (IF) e o Índice de Cobertura (IC), dentre os quais citam-se: Pereira (1989), Castilho (1994), Freitas (2004), Pereira (2008), Silva e Almeida (2010) e Damião (2011).

No entanto, existem outros índices, como o Índice de Restrição do Comércio, o índice desenvolvido por Fink e Braga (1999), que possibilita classificar, por ordem de importância, uma variável não quantitativa, naquele caso, o nível das políticas de proteção ao Direito Intelectual, podendo ser utilizado, conforme os autores, em modelos econométricos visando mensurar seu efeito sobre o comércio (MIRANDA, 2001).

De acordo com Damião (2011), Silva e Almeida (2011), Henson et al. (1999) e Laird (1996), a análise de inventário tem sua relevância para o conhecimento da natureza informacional das notificações, bem como para o cálculo de índices quantitativos. No entanto, alguns autores, como o próprio Laird (1996) e Pereira (1989), alertam para o problema referente à endogeneidade das ponderações do valor da importação. De acordo com esses autores, uma determinada medida não tarifária, imposta por um país, pode ser tão restritiva que limita totalmente as exportações para este país. Assim, o seu peso no cômputo dos indicadores será zero, subestimando a proporção das exportações que são afetadas pelas medidas não tarifárias. Pereira (1989) afirma que este problema impede que esses índices captem adequadamente os efeitos das medidas não tarifárias, limitando seu uso e interpretação.

Com o objetivo de analisar quanto das exportações brasileiras de uva foram sujeitas a medidas SPS e TBT, utilizou-se somente o índice de Cobertura, $I C_{j}$, uma vez que o $I F$ é calculado com base em um fluxo de $m$ produtos e, no caso de apenas um produto, como neste trabalho, o IF será sempre a unidade.

O $I C_{j}$, segundo Silva e Almeida (2010), leva em consideração o valor da exportação de uma mercadoria, sujeita a uma determinada notificação no país j. Este índice é definido como:

$$
I C=\left[\frac{\sum_{n=I}^{j}(V j \cdot N j)}{\sum_{n=I}^{j}(V j)}\right]
$$

em que $V j$ é o valor da uva exportada pelo Brasil para o país j; e $\mathrm{Nj}$ é uma variável binária, sendo 1 se houver uma notificação sobre a uva e 0 , caso contrário.

O IC varia entre 0 e $1^{7}$, sendo 0 quando não houver nenhuma notificação na OMC e 1 quando todos os parceiros comerciais do país exportador tiverem emitido pelo menos uma notificação.

7. O IC pode ser expresso também em porcentagem, basta multiplicá-lo por 100. Neste caso, ele mede a porcentagem da exportação (importação) que está sujeita a uma notificação. 


\subsection{Procedimento de Análise}

O custo de comercialização, ou custo de comércio $T_{i j t}$, pode ser expresso em termos das tarifas e das barreiras não tarifárias. A equação (6) relaciona o custo de comércio com as tarifas médias aplicadas pelo país importador $j$ ao país exportador $i\left(\right.$ tari $\left._{j i t}\right)$, com as medidas sanitárias e fitossanitárias impostas pelo país importador $j$ ao país exportador $i$ no ano $t\left(S P S_{j i t}\right)$ e as medidas técnicas impostas pelo país importador $j$ ao país exportador $i$ no ano $t\left(T B T_{j i t}\right)$ :

$\ln \left(T_{i j t}\right)=\beta_{5} \ln \left(1+\right.$ tarif $\left._{j i t}\right)+\beta_{6}\left(S P S_{j i t}\right)+\beta_{7}\left(T B T_{j i t}\right)$

Para verificar o impacto das notificações SPS e TBT na exportação de uva brasileira, utilizou-se o modelo apresentado a seguir, equação 7, derivado da equação 4 , com base no trabalho de Burnquist e Sousa (2010):

$$
\begin{aligned}
& \ln \left(M_{i t}\right)=\gamma_{i}+\gamma_{t}+\beta_{1} \ln \left(G D P_{j t}\right)+\beta_{2} \ln \left(G D P b r_{t}\right)+ \\
& +\beta_{3} \ln \left(\text { dist }_{i j}\right)+\beta_{4} \ln \left(1+\text { tarif }_{j i t}\right)+\beta_{5}\left(S P S_{j i t}\right)+ \\
& +\beta_{6}\left(T B T_{j i t}\right)+\beta_{7}\left(P I F_{t}\right)+\varepsilon_{j i, t}
\end{aligned}
$$

em que $M_{i j t}$ representa as importações pelo país $j$ do país $i$ no ano $t ; t=1995$ a 2009; $\gamma_{t}$ representa variáveis binárias para os anos da amostra; $\gamma_{t}$, as variáveis binárias para os pares de países; $G D P_{j t}$ e $G D P b r_{t}$ representam, respectivamente, o Produto Interno Bruto do país importador $j \mathrm{e}$ do Brasil; dist ${ }_{i j}$ representa a distância do Brasil ao país importador $j$; tarif $f_{j}$ representa a tarifa média aplicada pelo país importador $j$; $S P S_{j i t} d u m m y$ que recebe o valor 1 se houver pelo menos uma notificação SPS do país importador $j$ no ano $t$; $T B T_{j i t}$ é uma dummy que recebe o valor 1 se houver pelo menos uma notificação TBT do país importador $j$ no ano $t$; $P I F_{t}$, variável binária, sendo 1 para $t=$ $2003, \ldots, 2009$; e $\varepsilon_{i j t}$ representa o erro.

Alguns autores, como Rose (2000) e Baldwin e Taglioni (2006), recomendam a estimação da equação gravitacional considerando dados em painel com efeitos fixos. De acordo com Micco,

8. As equações 1 a 4 foram obtidas diretamente do trabalho de Anderson e Van Wincoop (2003). Já as equações 6 e 7 são equações modificadas do trabalho de Anderson e Van Wincoop (2003).
Stein e Ordoñez (2003), quando se usam dados em painel, a inclusão de dummies para pares de países e para o tempo elimina parte do viés causado pela correlação entre as seções cruzadas. Já conforme Baldwin e Taglioni (2006), os efeitos fixos eliminam o viés causado por características não observáveis que são correlacionadas com os termos de resistência multilateral de comércio. Assim, a equação (7) é estimada por Mínimos Quadrados Ordinários (MQO), considerando-se efeitos fixos para os países e para o tempo. Essa foi também estimada por efeitos aleatórios, resultados presentes na Tabela 3A.

\subsection{Fonte de dados}

A Tabela 1 contempla a definição, a descrição e a fonte dos dados de todas as variáveis utilizadas neste trabalho.

Os dados referentes ao PIB e à importação de uva dos países importadores são anuais. Os dados sobre importação foram obtidos utilizando o Sistema Harmonizado de seis dígitos ( $\mathrm{SH}$ a seis dígitos). Neste caso, foram utilizados os dados das importações em vez dos dados das exportações devido ao fato de grande parte dos trabalhos empíricos utilizarem importações, pois são de melhor qualidade do que os dados referentes às exportações (BURNQUIST e SOUZA, 2010).

Foram selecionados como países importadores a Alemanha, Argentina, Bélgica, Irlanda, Noruega, Holanda, Reino Unido e Estados Unidos, principais importadores de uva do Brasil no período de 1995 a 2009 (ver Tabela 1A).

Para este trabalho, foram consideradas apenas as notificações emitidas pela União Europeia, Estados Unidos e Argentina9. Para isso, foram coletadas as notificações quando eram relaciona-

9. Algumas notificações não explicitam os códigos do sistema harmonizado. Desse modo, além da pesquisa pelo código $\mathrm{SH}$, foi realizada também uma pesquisa com o termo uva (grape), fruta (fruit). As notificações referentes à uva foram incorporadas à análise. As notificações referentes a frutas, sem mencionar nenhum código do sistema $\mathrm{SH}$, também foram consideradas na análise. As notificações referentes especificamente à uva seca (dried grape) não foram consideradas na análise, visto que os dados de importações são para uvas in natura. 
Tabela 1. Definição, descrição e fonte das variáveis utilizadas neste estudo

\begin{tabular}{ccc}
\hline Variáveis & Descrição & Fonte \\
\hline$M$ & Valor da importação de uva brasileira (em dólares) \\
GDPbr & PIB do Brasil em dólares & UMCONTRADE 2011 \\
GDP & PIB dos países importadores de uva brasileira em dólares & Dados Estatísticos do Banco Mundial \\
dist & Distância entre a capital brasileira e a capital do país & Dados Estatísticos do Banco Mundial \\
importador em KM & Centre D’Estudes Prospectives et \\
SPS & Variável binária que recebe o valor 1 se o país importador tiver & d'Informations Internationales (CEPII) \\
& emitido uma notificação SPS à OMC e 0, caso contrário. & OMC, Documentos Online \\
TBT & Variável binária que recebe o valor 1 se o país importador tiver & OMC, Documentos Online \\
tarif & emitido uma notificação TBT à OMC e 0, caso contrário. \\
PIF & Valor da tarifa imposta à uva brasileira pelo país importador & Base de dados WITS \\
\hline
\end{tabular}

Fonte: Elaboração dos autores.

das ao $\mathrm{SH}$ com dois dígitos (neste caso frutas ou “08"), ou especificadas ao $\mathrm{SH}$ com quatro dígitos (neste caso para uva e seus derivados, ou "0806") e ao $\mathrm{SH}$ com seis dígitos (neste caso uva in natura ou “080610”).

\section{Resultados e discussões}

Esta seção foi dividida em duas partes. $\mathrm{Na}$ primeira, encontra-se uma análise das notificações ocorridas no período, em que foram consideradas apenas as notificações impostas pelos países importadores de uva brasileira, selecionados para este trabalho, descritas no tópico 4.3, tanto em termos do grupo frutas em geral, ou SH com dois dígitos (08 no caso de frutas), quanto em termos do grupo uva in natura, ou SH com seis dígitos (0806.10 no caso da uva in natura). Na segunda parte, são apresentados e discutidos os resultados do modelo econométrico.

\subsection{Resultado da Análise de Inventário}

\subsubsection{Análise das Notificações}

O primeiro procedimento foi a coleta da quantidade total de notificações, emitidas pelos oito países selecionados para este trabalho, tanto relativas ao setor frutícola como um todo, $\mathrm{SH}$ com dois dígitos (08), quanto a uvas, $\mathrm{SH}$ com quatro dígitos (0806) e com seis dígitos (0806.10). A Figura 1 mostra a quantidade total de notificações do sistema $\mathrm{SH}$ com dois dígitos, não incluindo as notificações do sistema $\mathrm{SH}$ a quatro e a seis dígitos, no período analisado (frutas), e o total de notificação do sistema SH com quatro e seis dígitos (uvas). Na Figura 1 está representada a soma das notificações SPS e TBT para as frutas e uvas.

Verificou-se número crescente de notificações até $2007^{10}$, quando se iniciou um processo de queda nos dois anos subsequentes. Quando se analisam as notificações para uva, esta característica se mantém com crescimento das notificações até 2007 e queda a partir dos dois anos posteriores. Pode-se notar, também, que grande parte das notificações totais de frutas foram direcionadas para a uva, mostrando que ela é muito afetada pela imposição das normas SPS e TBT.

10. O ano de 2007 apresentou número elevado de notificações, principalmente quando se analisam as notificações para frutas em geral. Um provável motivo pode ser o fato de, conforme nota emitida pelos EUA na OMC, de que o APHIS, parte do USDA, responsável pela regulamentação das medidas de caráter sanitário e fitossanitário, ter revisado e reorganizado os regulamentos relativos à importação de frutas e legumes para consolidar os requisitos de aplicabilidade geral e eliminar requisitos redundantes, atualizar termos e remover exigências obsoletas. Neste caso, novas medidas foram aplicadas e outras foram desconsideradas. 
Figura 1. Total de notificações, SPS e TBT, para fruta, ou SH com dois dígitos, desconsiderando-se as notificações referentes ao sistema SH 0806 e 0806.10, e para uva, ou SH 0806 e 0806.10, 1995 a 2009.

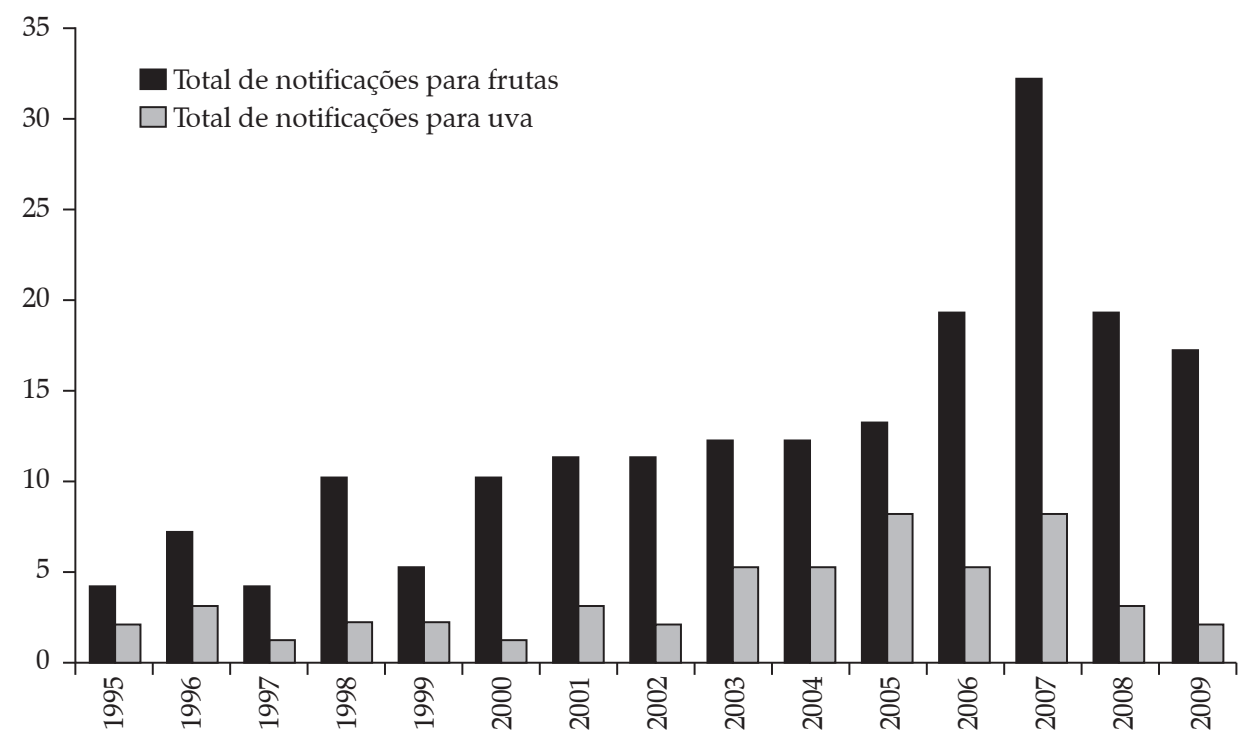

Fonte: Dados da pesquisa.

Quando se analisa a Figura 2, que mostra a evolução das importações no período junto ao número de notificações técnicas, sanitárias e fitossanitárias para uva, considerando-se apenas os países selecionados para esta pesquisa, verifica-se que as notificações SPS e TBT acom- panharam a evolução das importações de forma bem similar. Nos períodos de queda das importações, houve número menor de notificações por parte dos países importadores e, em período de expansão das importações, houve aumento das notificações.

Figura 2. Evolução das importações (em 10 milhões de dólares) e das notificações para o produto analisado no sistema SH com seis dígitos, levando-se em consideração apenas os países selecionados para a pesquisa, de 1995 a 2009.

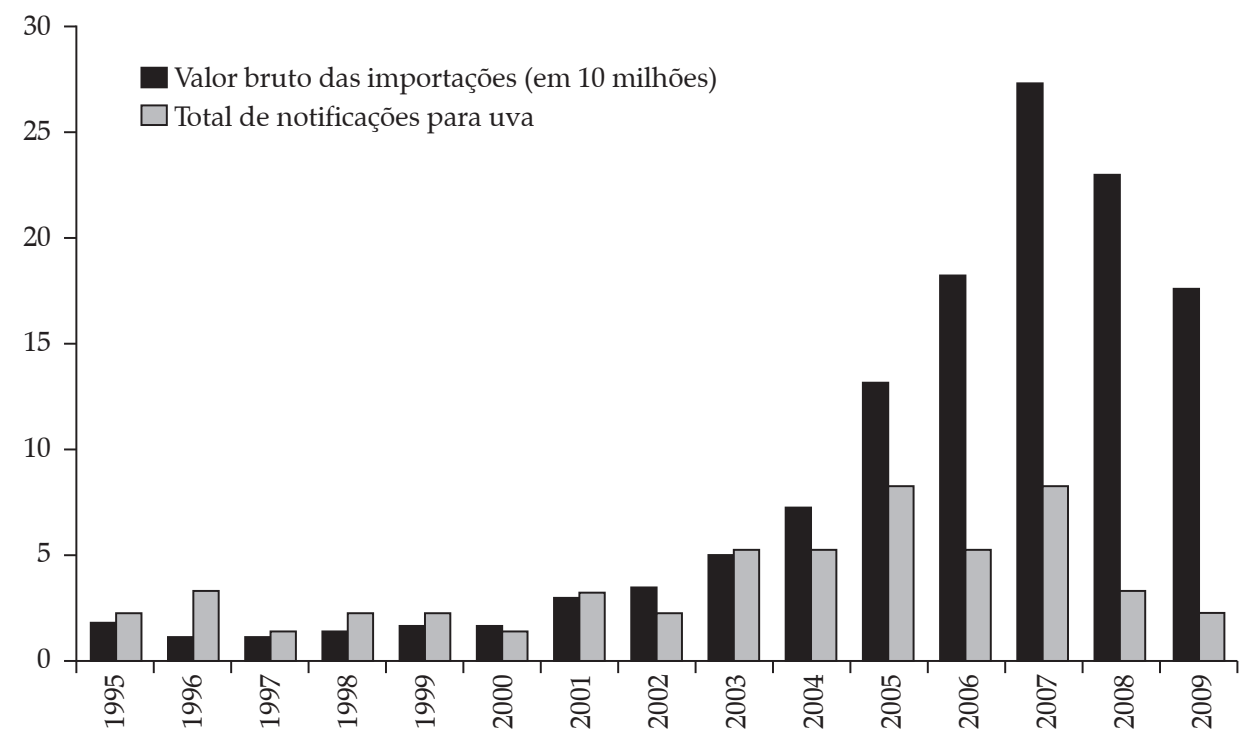

Fonte: Dados da pesquisa. 
É interessante analisar os dois últimos anos da série, 2008 e 2009, em que ocorreu uma forte queda das emissões de notificações por parte dos países importadores de uva, porém, não houve uma queda tão acentuada do valor das importações. Portanto, levando-se em consideração a Figura 2, é de se esperar uma relação positiva entre as notificações técnicas, sanitárias e fitossanitárias impostas à uva brasileira com a importação de uva, o que permite supor que este tipo de notificação para a uva brasileira foi facilitador do comércio.

Analisando-se as notificações por destino (Argentina, União Europeia, que compreende os cinco países europeus escolhidos na análise, e Estados Unidos), observa-se que a Argentina foi o país que menos notificou e os Estados Unidos foram os que mais notificaram, tanto para frutas

Figura 3. Total de medidas técnicas, sanitárias e fitossanitárias notificadas ao Brasil, pela União Europeia, Estados Unidos e Argentina, para frutas de 1995 a 2009

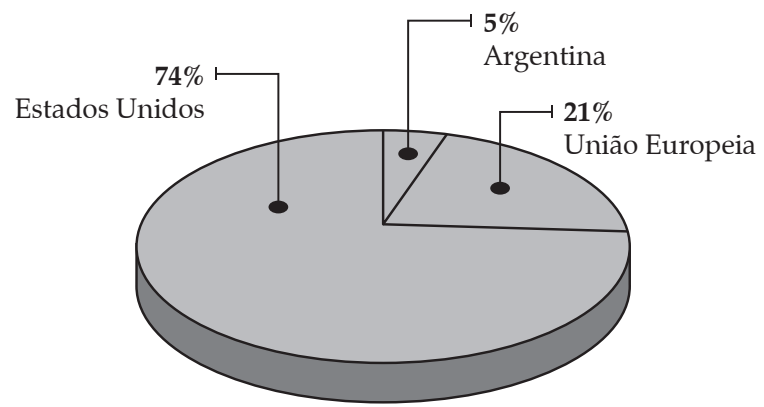

Fonte: Dados da pesquisa. no sistema SH com dois dígitos quanto para o sistema $\mathrm{SH}$ com seis dígitos. As Figuras 3 e 4 mostram esses dados.

\subsubsection{Análise do Índice de Cobertura}

O IC, que leva em consideração o valor das exportações sujeito à imposição de notificações técnicas, sanitárias e fitossanitárias em relação ao valor total das exportações, para os países selecionados, foi calculado tanto para as medidas SPS quanto para TBT. Na Tabela 2, encontram-se os resultados do índice.

Em alguns anos, o IC foi zero em decorrência da inexistência de medidas SPS e TBT no comércio do produto, apesar da existência de exportação de uva do Brasil para os seus parceiros comerciais no período (ver Tabela 2A).

Figura 4. Total de notificações para uva emitidas pela União Europeia, Estados Unidos e Argentina, de 1995 a 2009

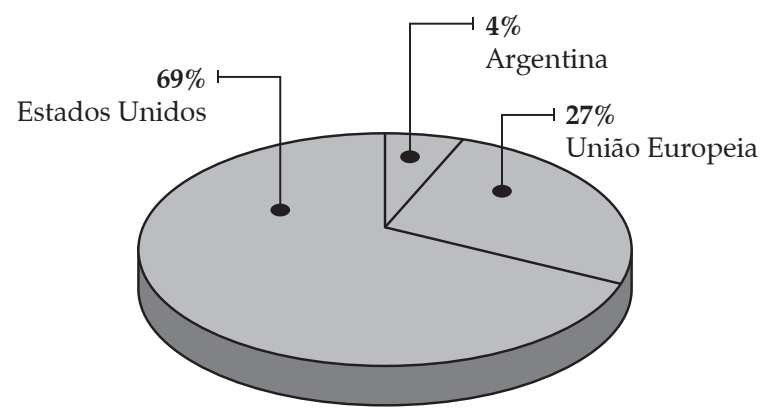

Fonte: Dados da pesquisa.

Tabela 2. Índice de cobertura, considerando-se os oito países selecionados, para as notificações SPS e TBT

\begin{tabular}{cccccc}
\hline Ano & SPS & TBT & Ano & SPS & TBT \\
\hline 1995 & 0,128 & 0,128 & 2003 & 0,900 & 0 \\
1996 & 0,046 & 0 & 2004 & 0,904 & 0 \\
1997 & 0,069 & 0 & 2005 & 0,914 & 0,134 \\
1998 & 0,171 & 0 & 2006 & 0,916 & 0,140 \\
1999 & 0 & 0.075 & 2007 & 0,912 & 0,137 \\
2000 & 0,110 & 0 & 2008 & 0,233 & 0,767 \\
2001 & 0,866 & 0 & 2009 & 0,137 & 0,137 \\
2002 & 0,101 & 0 & & & \\
\hline
\end{tabular}

Fonte: Resultado da pesquisa. 
Tabela 3. Resultados do modelo gravitacional estimado para o comércio internacional de uva do Brasil para seus principais parceiros comerciais

\begin{tabular}{ccccc}
\hline & Coeficiente & Erros padrão Robustos & Estatística z & P $>$ Z \\
\hline gdp & 0,339 & 0,905 & 0,37 & 0,709 \\
gdpbr & 2,268 & 0,733 & 3,10 & 0,003 \\
sps & 1,559 & 0,543 & 2,87 & 0,005 \\
tbt & 1,259 & 0,979 & 1,29 & 0,202 \\
tarif & 7,258 & 8,417 & 0,86 & 0,391 \\
dist & $-0,034$ & 0,587 & $-0,06$ & 0,954 \\
pif & 0,319 & 0,527 & 0,61 & 0,546 \\
\hline No de observações & 120 & & $\mathrm{R}^{2}$ & 0,7571 \\
Teste F (25, 94) & 31.17 & & Root MSE & 1,1845 \\
Prob>F & 0,000 & & \\
\hline
\end{tabular}

Obs: gdp: PIB do país importador; gdpbr: PIB do Brasil; sps: variável binária referente às medidas SPS; tbt: variável binária referente às medidas TBT; tarif: tarifa imposta pelo país importador; dist: distância entre a capital brasileira e a capital do país importador; pif: variável binária que capta o efeito do sistema PIF.

Fonte: Resultado da pesquisa.

O índice calculado para as notificações SPS foi muito elevado no período de 2003 a 2007, com drástica queda em 2008; manteve-se baixo em 2009 e muito baixo no período de 1995 a 2000 e em 2002. Pela Tabela 1A, nota-se que, nos anos em que os países pertencentes à União Europeia notificaram medidas SPS à OMC, o IC foi elevado e, nos em que não houve notificação por estes países, o IC foi baixo.

Comparando-se os resultados do IC com os de SPS na Figura 2, pode-se notar que o índice foi baixo no período em que a exportação de uva brasileira foi baixa, e, elevado no período em que houve crescimento considerável das exportações brasileiras. No período de 2003 a 2006, período em que o IC foi elevado, mais de $90 \%$ das exportações de uvas foram sujeitas a, no mínimo, uma notificação a cada ano do período, e o crescimento das exportações de uva foi de cerca de 80\%. Já no período de 1995 a 2000, período em que o IC foi muito baixo, dado que reduzida parcela da exportação de uva foi sujeita a pelo menos uma notificação, o crescimento das exportações de uva foi de $16 \%$.

No caso das medidas TBT, somente em 2008 o índice foi elevado, mostrando que os países importadores de uva brasileira impõem número maior de notificações SPS e poucas TBT. Em diversos anos, o IC comparado com as TBT foi nulo devido à ausência de notificação. Portanto, é de se espe- rar que as medidas TBT não atuem como medidas protecionistas, pois uma parcela pequena das exportações brasileiras é afetada por tais medidas.

\subsection{Efeitos das medidas sanitárias, fitossanitárias e técnicas sobre o comércio internacional da uva brasileira}

Ao contrário do Índice de Cobertura calculado na seção anterior, que visa identificar o total das exportações de uva sujeitas às exigências sanitárias, fitossanitárias e técnicas, a estimação do modelo gravitacional permite identificar os efeitos dessas MNT sobre o referido comércio.

Na estimativa deste modelo, como mencionado no item 3.2, foi construído um painel para verificar o impacto das medidas SPS e TBT e da variável PIF no comércio internacional de uva brasileira. O modelo foi estimado pelo método dos Mínimos Quadrados Ordinários, considerando efeitos fixos para países importadores e para os anos. Os coeficientes estimados, já com os erros padrão robustos ${ }^{11}$, encontram-se na Tabela 3.

Pelos resultados do modelo estimado, verifica-se que, conjuntamente, as variáveis explicam

11. Foram feitos os testes de autocorrelação, sendo rejeitada a hipótese de correlação entre as variáveis e os resíduos, e de heteroscedasticidade, sendo identificada sua presença no modelo. Para solucionar este problema, foi calculado o erro padrão robusto, segundo o trabalho de White (1980). 
as variações no comércio de uva, conforme aponta o p-valor da estatística F. Com relação à significância individual das variáveis, verificou-se que somente as relativas às exigências SPS e ao PIB do Brasil foram estatisticamente significativas.

O coeficiente positivo e estatisticamente significativo encontrado para o PIB do Brasil está coerente com a expectativa e indica que aumentos na renda do país contribuem para o aumento do comércio da fruta. Certamente, o aumento da renda favorece o aumento da produção e também do cultivo de uma fruta de qualidade, de tal forma que o comércio internacional é aumentado. Por outro lado, o fato de o PIB dos importadores não ter apresentado efeitos sobre as importações do produto pode indicar que, quando a renda de um país importador cresce, ele não necessariamente aumenta o consumo de determinado produto específico. Ele pode passar a adquirir mais de outros produtos ou mesmo substituir o consumido anteriormente. Desse modo, é justificável que o PIB dos importadores não seja significativo no modelo de gravidade estimado. Tal fato está de acordo com o estudo da Unctad (2008).

Quanto aos efeitos das MNT, caracterizados aqui como a existência de notificações aos acordos TBT e SPS, apenas aqueles direcionados às exigências sanitárias e fitossanitárias (SPS) afetaram o comércio. Como a variável SPS foi significativa e com valor positivo, pode-se inferir que as medidas sanitárias e fitossanitárias auxiliaram as exportações de uva do Brasil. Neste caso, as medidas sanitárias e fitossanitárias não foram barreiras ao comércio, ou seja, não caracterizaram medidas protecionistas. Como já mencionado, Moenius (2004) afirma que a normalização tende a facilitar o fluxo de comércio quando ela reduz o custo de transação associado à informação incompleta dos agentes. Portanto, pode-se afirmar, pelo modelo econométrico, que as medidas SPS foram importantes para o aumento do fluxo de comércio entre os países analisados por reduzir tais custos de transação. Resultados similares foram observados em trabalhos de Moenius (2004), Disdier et al. (2004), Josling et al. (2004), Roberts e Unnevehr (2005) e Burnquist e Souza (2010).
Por outro lado, não foram verificados efeitos das medidas técnicas sobre o referido comércio. Tal fato pode indicar que os produtores atenderam às exigências TBT de tal forma que o comércio não se alterou em função da existência de tais medidas.

Conforme os dados coletados para a tarifa, no período analisado, houve pequena redução tarifária e, neste caso, era esperado que essa diminuição resultasse em aumento das exportações, comportamento decorrente da queda do preço do produto. No entanto, as tarifas adotadas pelos importadores em relação às exportações de uva do Brasil não afetaram o comércio, dado que o coeficiente desta variável não apresentou significância estatística. De acordo com Protas e Camargo (2011), a partir do início da década de 2000, os preços da uva tiveram um período crescente que, possivelmente, ocorreu devido ao fato de a região do Vale do São Francisco, grande exportadora de uva, ter tido sua produção num período de escassez no cenário internacional, garantindo um preço mais elevado. Ademais, de acordo com Mello (2009), na década de 2000, a vitivinicultura passou por um processo de valorização do produto, sendo a qualidade um dos fatores mais importantes. Assim, tais fatores podem justificar a ausência de efeito da tarifa sobre o comércio, pois, embora tenha ocorrido redução tarifária, não houve diminuição de preço, mas, sim, aumento do mesmo, favorecido pela oferta de uva de qualidade num período de escassez. Com relação à variável distância, apesar de o sinal do seu coeficiente apontar a esperada relação inversa entre custo de transporte e comércio, não se observou significância estatística. Isso aponta que os referidos custos não afetaram o comércio do produto.

Em relação à variável PIF, se mostrou não significativa, o que pode ser explicado pelo requerimento de outros tipos de certificação. De acordo com Andrigueto et al. (2008), em 2007, foram produzidas 167.268 toneladas de uva sob o regime da Produção Integrada de Frutas, ou seja, 12\% do total da uva produzida no País, que, conforme dados do IBGE, foi de 1.354.960 toneladas. A des- 
peito, a quantidade de frutas sobre o sistema PIF foi superior ao volume exportado de uva, que foi de quase 80 mil toneladas em 2007. Como informado no tópico 2.2, a uva produzida sob o sistema PIF precisa ser aceita por um órgão internacional competente para ser exportada e, que outros selos de certificação são aceitos pelos principais importadores de uva no Brasil - Estados Unidos e União Europeia. Tal comportamento pode, assim, indicar que apenas o selo PIF não seja suficiente para aumentar as exportações de uva brasileira, sendo necessária uma certificação adicional. Este resultado não significa que o sistema PIF não seja importante. O fato de um produtor já implantar tal sistema na produção de uva torna mais fácil à adequação das exigências impostas pelos países importadores e que não estão presentes no sistema PIF.

Por fim, na Tabela 3A, estão os resultados para o modelo de efeitos aleatórios como uma forma de comparação com o modelo de efeitos fixos aqui apresentado. Os resultados foram bem parecidos, sendo, de modo geral, a significância da variável TBT a única diferença.

\section{Conclusão}

O presente trabalho buscou analisar o impacto das medidas SPS e TBT no comércio de uva do Brasil, em que foram avaliados oito países. Buscou também verificar se o sistema PIF uva, implantado em 2003, afetou, de forma positiva, as exportações de uva.

Em se tratando das medidas SPS e TBT, os resultados encontrados parecem confirmar proposições teóricas, também discutidas em outros trabalhos, de que regulamentos e normas sanitárias, fitossanitárias e técnicas em determinados casos podem auxiliar o comércio. Assim, pode-se inferir que os produtores brasileiros de uva estão conseguindo se adequar às exigências sanitárias, técnicas e fitossanitárias estabelecidas pela comunidade internacional. Dado que em determinadas situações os processos de normalização e regulamentação nos mercados podem auxiliar o comércio ao reduzir custos de transação associados à informação incompleta, pode ser este processo a causa do efeito positivo das medidas SPS e TBT nas exportações de uva.

OsistemaPIFdeuva, elaboradopeloMinistério da Agricultura Pecuária e Abastecimento (Mapa), mostrou não ser significativo para o comércio internacional de uva. Ressalta-se, entretanto, que o sistema PIF apresenta benefícios de carácter técnicos já citados em alguns trabalhos, tais como aumento da produtividade e da qualidade das frutas, melhoria do meio ambiente e redução de agrotóxicos e da presença de resíduos químicos nas frutas - sendo este um fator importante num período de crescente imposição de medidas SPS.

Pela análise das notificações e do inventário, verificou-se estreita relação positiva entre a evolução das notificações e a evolução das importações de uvas pelos principais parceiros comerciais do Brasil. Esta relação pode ter ocorrido devido ao objetivo da imposição de barreiras sanitárias, fitossanitárias ou técnicas, ou seja, por protecionismo. Porém, pelo procedimento econométrico utilizado, foi descartado o uso de tais medidas como protecionismo, sendo que as medidas sanitárias e fitossanitárias favoreceram o fluxo de comércio entre os países envolvidos.

Para trabalhos futuros, sugere-se verificar o impacto das notificações SPS e TBT no fluxo de comércio de produtos processados de uva e também o de outras medidas no fluxo de comércio, como medidas antidumping, subsídios, cotas, entre outras medidas não tarifárias.

\section{Referências bibliográficas}

ALICEWEB. Sistema de consulta. Disponível em: $<$ http:// aliceweb.desenvolvimento.gov.br/>. Acesso em: 20 jan. 2012

ANDERSON, J. E. A theoretical foundation for the gravity equation. The American Economic Review, v. 69, n. 1, p. 106-116, 1979.

ANDERSON, J. e WINCOOP, E. Gravity with Gravitas: a solution to the border puzzle. American Economic Review, Nashville, v. 93, n. 1, 2003. 
ANDRIGUETO, J. R. et al. Produção Integrada de Frutas e Sistema Agropecuário de Produção Integrada no Brasil. 2008, 24p.

AZEVEDO, A. F. Z. O efeito do MERCOSUL sobre o comércio: uma análise com o modelo gravitacional. Pesquisa e Planejamento Econômico, v. 34, n. 2, 2004, p. 307-340.

BAIER, S. L. e BERGSTRAND, J. H. Do free trade agreements actually increase member's international trade? Journal of International Economics, v. 71, 2007, p. 72-95.

BALDWIN, R. e TAGLIONI, D. Gravity for dummies and dummies for gravity equations. National Bureau of Economic Research, NBER WORKING PAPER, $31 \mathrm{p}$. 2006. Disponível em: <http://www.nber.org/papers/ w12516>. Acesso: 15 fev. 2013.

BANCO MUNDIAL. World Integrated Trade Solution. Disponível em: <wits.worldbank.org > Acesso em: 24 jan. 2011.

BERGSTRAND, J. The gravity equation in international trade: some microeconomic foundations and the empirical evidence. Review of Economics and Statistics, v. 67, p. 474-481, 1985.

BUAINAIN, A. M. e BATALHA, M. O. Cadeia produtiva de frutas. Brasília: IICA: MAPA/SPA, v. 7, 2007. 105 p.

BURNQUIST, H. L. e SOUZA, M. J. P. Impactos da regulamentação sanitária sobre o comércio: positivo, negativo ou ambíguo? In: Notificações aos Acordos de Barreiras Técnicas (TBT) e Sanitárias (SPS) da OMC: transparência comercial ou barreiras não tarifárias? Editor: Orlando M. da Silva. Viçosa, MG, 2010, 239p.

CAJAZEIRA, J. E. R. Normalização e barreiras nãotarifárias: uma análise da influência das normas socioambientais de gerenciamento no comércio internacional. Tese de Doutorado em Administração de Empresas, Escola de Administração de Empresa de São Paulo, São Paulo, SP, 2008, p. 225.

CÀRRÉRE, C. Revisiting the effects of regional trade agreements on trade flows with proper specification of the gravity model. European Economic Review, v. 50, 2006, p. 223-247.

CASTILHO, M.R. Barreiras não-tarifárias: o caso da imposição de restrições ambientais sobre as exportações brasileiras de papel e celulose. Rio de Janeiro, 1994. 106p. Dissertação (Mestrado) - Universidade Federal do Rio de Janeiro.

CENTRE D'ESTUDES PROSPECTIVE ET D'INFORMATIONS INTERNATIONALES - CEPII.
Distances. Disponível em: <http://www.cepii.fr/ francgraph/bdd/distances.htm > . Acesso em: 05 jan. 2011.

CINTRA, R. F., VITTI, A. e BOTEON, M. Análise dos impactos da certificação de frutas brasileiras para o mercado externo, 2005. Disponível em: <http//:www.cepea. esalq.usp.br/hortifruti>.

DAMIÃO, D. N. Impactos dos instrumentos regulatórios SPS e TBT sobre o comércio de carne bovina nos países do MERCOSUL. Dissertação (Mestrado em Economia), Viçosa, MG, 2011, 156 p.

DIAS, A. R. Barreiras não-tarifárias às exportações de carne bovina do Rio Grande do Sul sob a ótica do Sistema Integrado Agronegocial (SIAN). Dissertação de Mestrado em Agronegócios, Universidade Federal do Rio Grande do Sul - UFRS, Porto Alegre, RS, 2003, p. 215.

DISDIER, A-C., FONTAGNÉ, L. e MIMOUN, M. The impact of regulations on Agricultural trade: evidence from the SPS and TBT agreements. American Journal of Agricultural Economics, v. 90, n. 2, maio 2008, 15p.

EMBRAPA - Empresa Brasileira de Pesquisa Agropecuária. Site: http://www.embrapa.br/

FARIAS, R. N. Efeitos da imposição de barreiras não tarifárias nas exportações brasileiras de mamão. Tese de doutorado em Economia Aplicada, Universidade Federal de Viçosa - UFV, Viçosa, MG, 2004, p. 149.

FERREIRA, M. D. P., LÍRIO, V. S. e MENDONÇA, T. G. Análise do perfil e grau de incidência de barreiras não tarifárias sobre as exportações brasileira de frutas selecionadas. Documentos Técnicos Científicos, v. 41, n. 4, out.-dez. 2010, 16p. Disponível em: < http://www.bnb. gov.br/projwebren/exec/artigoRenPDF.aspx?cd_artigo_ ren=1214 > . Acesso em: 20 jan. 2011.

FINK, C. e BRAGA, A. P. How stronger protection of intellectual property rights affects international trade flows. Washington, D.C.: World Bank, 1999. 23p. (Working Paper, 2051).

FREITAS, R. E. Barreiras comerciais sobre produtos agroindustriais brasileiros na União Europeia. Tese (Doutorado em Ciências: Economia Aplicada), ESALQUSP, São Paulo, 2004, 155 p.

HENSON, S. et al. The impact of sanitary and phytosanitary measures on developing countries exports of agricultural and food products. In: The Conference on Agricultural and The New Trade Agenda in the WTO 2000 Negotiations. Genève: World Bank/WTO, Oct. 1999. 21 p.

HENSON, S. e LOADER, R. Barriers to Agricultural Exports from Developing Countries: The Role of 
Sanitary and Phytosanitary Requirements. World development, v. 29, n. 1, 2001, p. 85-102.

IPEADATA, Instituto de Pesquisa Econômica Aplicada. $<$ www.ipeadata.gov.br> 2011.

JOSLING, T., ROBERTS, D. e ORDEN, D. Food regulations and trade: toward a safe and open global system. Washington: Institute for International Economics, 2004. 260p.

JUNQUEIRA, B. A. Identificação e análise de barreiras nãotarifárias sobre as exportações brasileiras de carne bovina. Dissertação de Mestrado em Economia Aplicada, Universidade Federal de Viçosa - UFV, Viçosa, MG, 2006, 156p.

LAIRD, S. Quantifying commercial policies. Geneve. Staff Working Paper, World Trade Organization. 1996. 43p.

MÁTYÁS, L. Proper econometric specification of the gravity model. The World Economic, v. 20, n. 3, 2002. Disponível em: <http:/onlinelibrary.wiley.com/ doi/10.1111/1467-9701.00074/pdf> . Acesso: 20 maio 2011.

MCCALLUM, J. National Borders Matter: Canada-U.S. Regional Trade Patterns. The American Economic Review, jun. 1995, p. 615-632.

MELLO, L. M. R. Área e produção de uvas: Panorama Mundial. Artigo Técnico - EMBRAPA Uva e Vinho, 2009, 6p. Disponível em: <http://www.cnpuv.embrapa.br/ publica/artigos/producaomundial.pdf $>$. Acesso em: 5 out. 2012.

MELLO, L. M. R. Vitivinicultura brasileira: Panorama 2009. EMBRAPA Uva e Vinho, 2010, 4p. Disponível em: <http://www.cnpuv.embrapa.br/publica/artigos/ prodvit2009vf.pdf>. Acesso: 20 jan. 2011.

MICCO, A., STEIN, E. e ORDOÑEZ, D. The currency union effect on trade: Early evidence from EMU. Economic Policy, v. 18, n. 37, 2003, p. 315-356.

MIRANDA, S. H. G. Quantificação dos efeitos das barreiras não-tarifárias sobre as exportações brasileiras de carne bovina. Tese de Doutorado em Ciências, área de concentração: Economia Aplicada, Escola Superior de Agricultura "Luiz de Queiroz", Universidade de São Paulo, Piracicaba, SP, 2001, p. 254.

MIRANDA, S. H. G. et al. Normas sanitárias e fitossanitárias: proteção ou protecionismo. Informações Econômicas. São Paulo - SP, v. 34, n. 2, p. 11, 2004.

MOENIUS, J. Information versus product adaptation: The Role of Standards in Trade. Kellogg School of Management, Northwestern University, 2004. (Working Paper). Disponível em: <http://ssrn.com/ abstract $=608022>$. Acesso: 20 jan. 2011 .
ORGANIZAÇÃO MUNDIAL DO COMÉRCIO (OMC). Central de registros de notificações. Disponível em: $<$ http://docsonline.wto.org/GEN_CRNsearch.asp $>$. Acesso em: 10 jan. 2011.

PEREIRA, L. V. Indicadores de incidência das barreiras não-tarifárias praticadas pelos países desenvolvidos contra as exportações brasileiras. Rio de Janeiro: FGV, 1989. 68p (Texto para Discussão Interna, 22).

PEREIRA, P. C. Inserção brasileira no mercado internacional de produtos lácteos: evolução e perspectivas. Tese (Doutorado em Ciências e Tecnologia de Alimentos), Viçosa, MG, 2008, 194 p.

PEREIRA, W. R. Histórico da OMC: construção e evolução do sistema multilateral de comércio, Conjuntura Internacional PUC-MINAS, Belo Horizonte, MG, 2005, 6p. Disponível em: <http:// www.pucminas.br/imagedb/conjuntura/CES_ARQ_ DESCR20050927090630.pdf?PHPSESSID =1a6f75b339c 894845fd56f84eb74ede8 >. Acesso em: 11 dez. 2010.

PROTAS, J. F. S. e CAMARGO, U. A. Vitinicultura brasileira: panorama setorial de 2010. IBRAVIN: Embrapa Uva e Vinho, SEBRAE - Brasília, DF. 109 p. 2011. Disponível em: <http://www.cnpuv.embrapa.br/ download.php?file $=$ publica/livro/vitivinicultura. pdf>. Acesso: 10 fev. 2013.

ROBERT, D. e UNNEVEHR, L. Resolving trade disputes arising from trends in food safety regulation: the role of multilateral governance framework. World Trade Review, n. 4, v. 3, p. 469-97, 2005.

ROSE, A. K. One money, one market: estimating the effect of common currencies on trade. Economic Policy, v. 30, p. 7-45, 2000.

ROSE, A. K. e SPIEGEL, M. M. A Gravity Model of Sovereign Lending: Trade, Default and Credit. NBER Working Paper, n. 9285, out. 2002, 21 p. Disponível em: $<$ http://www.nber.org/papers/w9285.pdf>. Acesso em: 2 abr. 2011.

SOUZA, E. P., CAMPOS, A. C. e LIMA, J. E. Análise de Intervenção aplicada às exportações brasileiras de melão. XLV Congresso da Sober, Londrina, PR, 2007, 15p.

SILVA, O., M. e ALMEIDA, F., M. A incidência das notificações aos acordos sobre medidas SPS e TBT da OMC nas exportações agrícolas do Brasil. In: Notificações aos Acordos de Barreiras Técnicas (TBT) e Sanitárias (SPS) da OMC: transparência comercial ou barreiras não tarifárias? Editor: Orlando M. da Silva. Viçosa, MG, 2010, 239p.

SILVA, O. M., ALMEIDA, F. M. e OLIVEIRA, B. M. Comércio internacional " $\mathrm{x}$ " intranacional no 
Brasil: medindo o efeito-fronteira. Nova Economia, v. 17, n. 3, sep./dez. 2007. Disponível em: <http:// www.scielo.br/scielo.php?script $=$ sci_arttext\&pi $\mathrm{d}=$ S0103-63512007000300003 $>$. Acesso: 2 abr. 2011.

SILVA, A. P. J. S., PEREIRA, P. O. e SANSEVERO, Y. C. V. A atuação internacional da ANVISA na aplicação dos acordos sobre as medidas SPS e TBT da Organização Mundial do Comércio In: Notificações aos Acordos de Barreiras Técnicas (TBT) e Sanitárias (SPS) da OMC: transparência comercial ou barreiras não tarifárias? Editor: Orlando M. da Silva. Viçosa, MG, 2010, 239p.

THORSTENSEN, V. OMC - Organização Mundial do Comércio: as regras do comércio internacional e a Rodada do Milênio. São Paulo: Aduaneiras, 1999. 406 p.
TINBERGEN, J. Shaping the world economy: suggestions for an international economy policy. New York: Twentieth Century Fund, 1962.

UNCOMTRADE - United Nations Commodity trade Statistic database. Disponível em: < http://comtrade. un.org/db > . Acesso em: 5 jan. 2011.

UNCTAD. Soluções de controvérsia: medidas sanitárias e fitossanitárias. Genebra: Nações Unidas, 2003. 66 p.

UNCTAD. Training package on trade policy analysis, Module 2. Ex-post Statistical Analysis, 2008. p. 114

WHITE, H. A heteroscedasticity consistent covariance matrix estimator and a direct test of heteroscedasticity. Econometria, London, v. 48, n. 3, p. 817-818, set. 1980. 
Tabela 1A. A Os maiores importadores de uva brasileira, no período de 1995 a 2000

\begin{tabular}{|c|c|c|c|c|c|}
\hline Ano & & & Países & & \\
\hline 1995 & Holanda & Reino Unido & Argentina & EUA & Alemanha \\
\hline 1996 & Holanda & Argentina & Reino Unido & Suíça & Alemanha \\
\hline 1997 & Holanda & Argentina & Reino Unido & Indonésia & Alemanha \\
\hline 1998 & Holanda & Argentina & Reino Unido & Uruguai & Canadá \\
\hline 1999 & Argentina & Holanda & Reino Unido & Alemanha & Finlândia \\
\hline 2000 & Holanda & Argentina & Reino Unido & Alemanha & Bélgica \\
\hline 2001 & Holanda & Reino Unido & Argentina & Alemanha & Bélgica \\
\hline 2002 & Holanda & Reino Unido & Alemanha & USA & Bélgica \\
\hline 2003 & Holanda & Reino Unido & USA & Alemanha & Noruega \\
\hline 2004 & Holanda & Reino Unido & USA & Alemanha & Noruega \\
\hline 2005 & Holanda & Reino Unido & USA & Noruega & Alemanha \\
\hline 2006 & Holanda & USA & Reino Unido & Noruega & Canadá \\
\hline 2007 & Holanda & Reino Unido & USA & Noruega & Bélgica \\
\hline 2008 & Holanda & USA & Reino Unido & Bélgica & Irlanda \\
\hline 2009 & Holanda & Reino Unido & USA & Bélgica & Irlanda \\
\hline
\end{tabular}

Fonte: Dados da pesquisa.

Figura 1A. Participação das exportações brasileiras no total mundial.

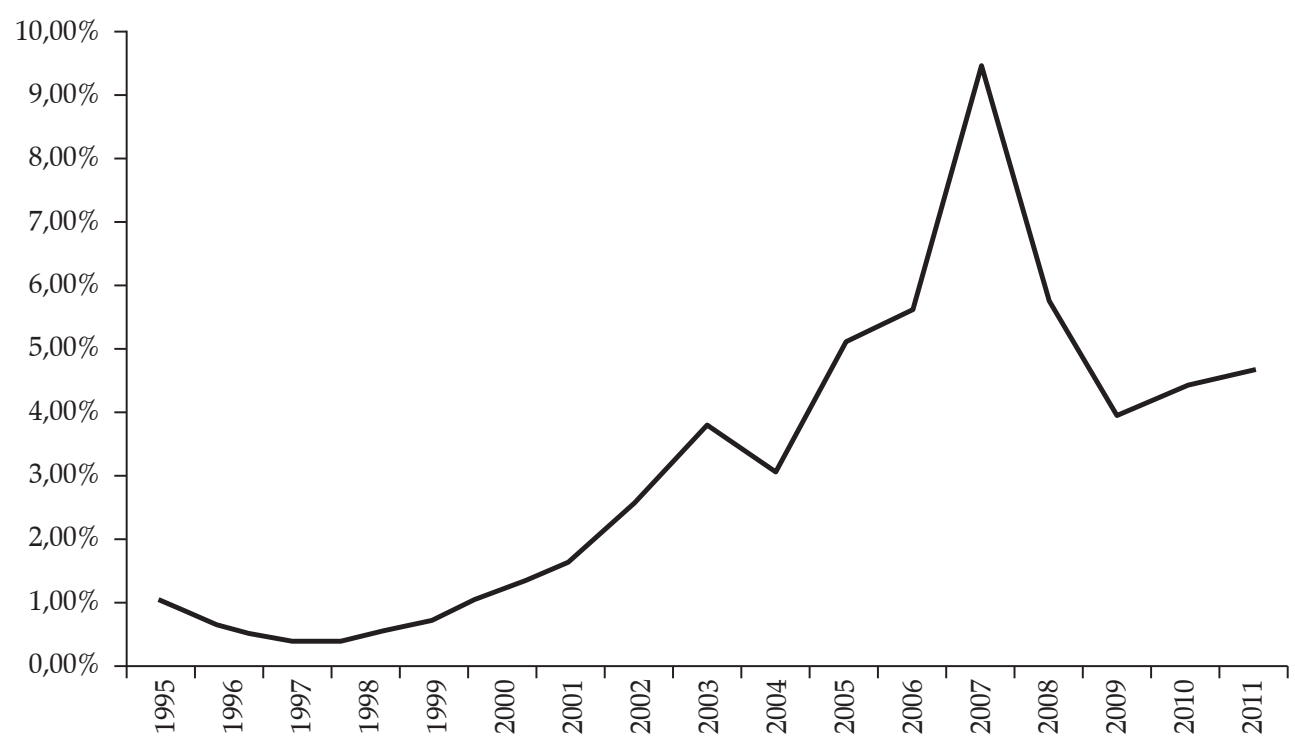

Fonte: Dados da pesquisa. 
Figura 2A. Valor total comercializado de uva no mundo no período de 1995 a 2009.

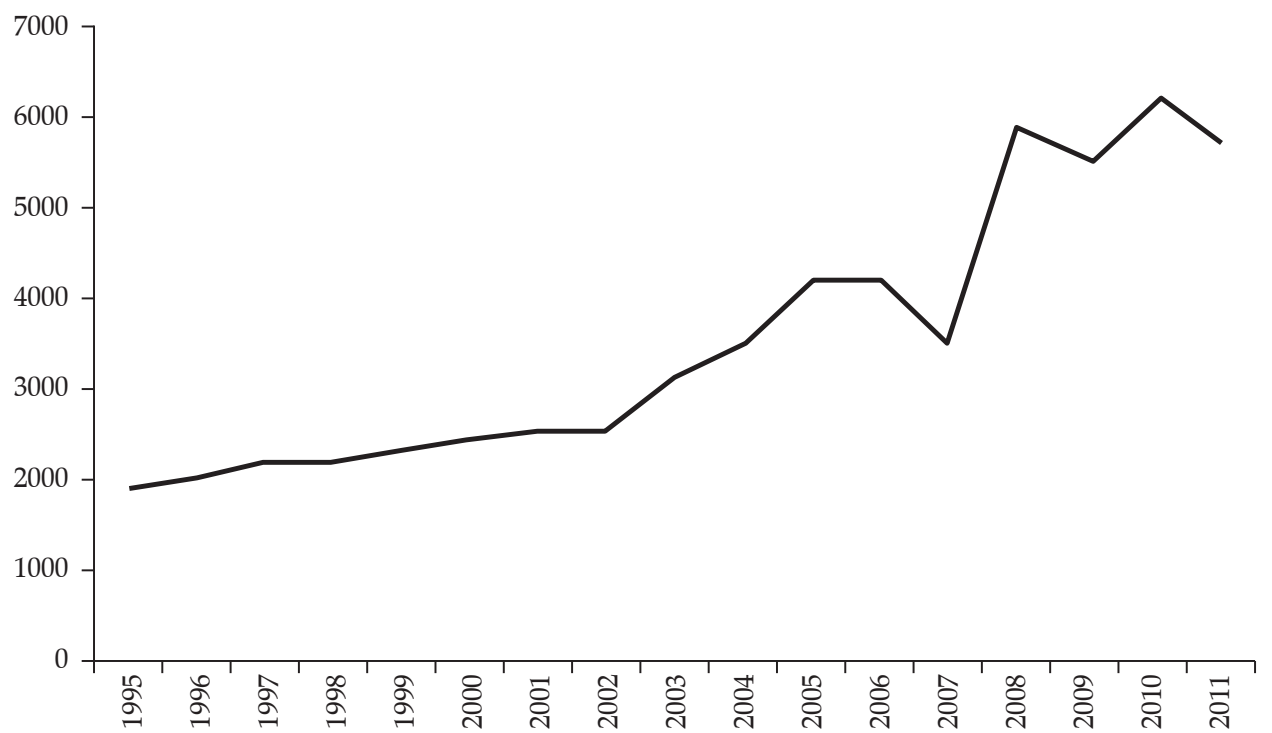

Fonte: Dados da pesquisa.

Tabela 2A. Países que notificaram medidas SPS e TBT à uva brasileira no período de 1995 a 2009

\begin{tabular}{lcc}
\hline Ano & Medidas SPS & Medidas TBT \\
\hline 1995 & Estados Unidos & Estados Unidos \\
1996 & Estados Unidos & Não Houve Notificação \\
1997 & Estados Unidos & Não Houve Notificação \\
1998 & Não Houve Notificação & Estados Unidos \\
1999 & Não Houve Notificação & Estados Unidos \\
2000 & Estados Unidos & Não Houve Notificação \\
2001 & Estados Unidos e Reino Unido & Não Houve Notificação \\
2002 & Estados Unidos & Não Houve Notificação \\
2003 & União Europeia e Estados Unidos & Não Houve Notificação \\
2004 & Estados Unidos e Reino Unido & Não Houve Notificação \\
2005 & União Europeia e Estados Unidos & Estados Unidos \\
2006 & União Europeia e Estados Unidos & Estados Unidos \\
2007 & União Europeia e Estados Unidos & Estados Unidos \\
2008 & Argentina e Estados Unidos & União Europeia e Estados Unidos \\
2009 & Estados Unidos & Estados Unidos \\
\hline
\end{tabular}

Fonte: Dados da pesquisa.

Tabela 3A. Resultado do modelo de efeitos aleatórios

\begin{tabular}{ccccc}
\hline & Coeficiente & Erro Padrão Robusto & Estatística $\mathbf{z}$ & P $>\mathbf{z}$ \\
\hline gdp & $-0,047$ & 0,346 & $-0,14$ & 0,892 \\
gdpbrasil & 5,461 & 2,094 & 2,61 & 0,009 \\
tarif & 9,683 & 13,125 & 0,74 & 0,461 \\
dist & $-0,067$ & 0,466 & $-0,14$ & 0,885 \\
sps & 1,496 & 0,263 & 5,69 & 0,000 \\
tbt & 1,149 & 0,537 & 2,14 & 0,032 \\
pif & $-4,401$ & 2,880 & $-1,53$ & 0,126 \\
\hline
\end{tabular}

Fonte: Resultados da pesquisa. 